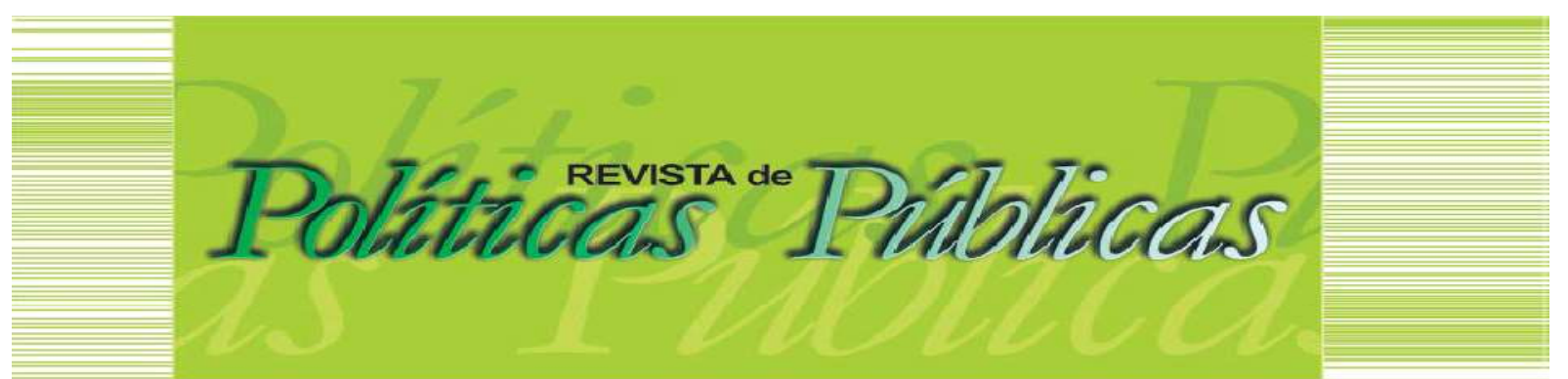

\title{
FAILURES IN BRAZILIAN PUBLIC SOCIAL PROGRAMS TO REDUCE EXTREME POVERTY: case study Porto Alegre for all
}

\author{
Gabriel R D Levrini ${ }^{1}$
}

\begin{abstract}
Poverty can be an economic circumstance, but it is also a political issue, since it directly influences several political decisions. The academic literature agrees that fundamental human needs have had, in fact, little development in their concept and scope within recent decades, although significantly changed happened in the Western way of accomplishing needs. We seek to understand different perspectives on possible different paths to a humanist articulation in the development of society. The goal of the research is through a humanistic approach based on Max Neef's theoretical precepts to understand the failure of the social program called Porto Alegre for All, in which less than $10 \%$ of the target population adopted the program. The research design had a qualitative phase with interviews with six target individuals, aiming to gain insights for the development of attributes and hierarchy of values for the use of the quantitative technique of joint analysis, made with a sample of 98 individuals. In our research the most important result was the attribute freedom, and the maternal pillar of the family is the great reference of these individuals.
\end{abstract}

Keywords: Extreme Poverty. Freedom. Social programs. Fundamentals human needs.

\section{Resumo}

A pobreza pode ser uma circunstância econômica, mas também é uma questão política. A literatura acadêmica concorda que o conceito das necessidades humanas fundamentais teve, de fato, pouco desenvolvimento na sua atualização e escopo nas últimas décadas, embora mudanças significativas tenham ocorrido no modo ocidental de atender às necessidades. Buscamos a compreensão de diferentes perspectivas sobre os possíveis caminhos diferentes para uma articulação humanista no desenvolvimento da sociedade. $O$ objetivo da pesquisa, é através de uma abordagem humanística baseada em preceitos teóricos de Max Neef compreender o fracasso do programa social denominado Porto Alegre para Todos, no qual menos de $10 \%$ da população-alvo adotou o programa. 0 design da pesquisa teve uma fase qualitativa com entrevistas com seis indivíduos target, com o objetivo de obter insights para o desenvolvimento dos atributos ehierarquia de valores para utilização da técnica quantitativa de análise conjunta, feita com uma amostra de 98 indivíduos. Na nossa pesquisa 0 resultado mais importantefoi 0 atributo liberdade, sendo que o pilar materno da familia e a grande referência destes individuos.

Palavras-chave: Extrema pobreza. Liberdade. Programas sociais. Necessidades fundamentais humanas.

Artigo recebido em: 27/09/2018 Aprovado em: 02/10/2019 DOI: http://dx.doi.org/10.18764/2178-2865.v23n2p786-806.

\footnotetext{
1 Agrônomo. Pós- Doutor em NeuroMarketing pela UFRGS. Doutor em Administração de Empresas pela Pontifícia Universidade Católica do Rio de Janeiro. Mestrado em International Finance - Pacific States University - Los Angeles -USA. Consultor de empresas com a Neurometrics Brasil. Professor de Pós- Graduação da ESPM, Faculty Full time. E-mail: levrini@terra.com.br
} 


\section{INTRODUÇÃO}

In his seminal article "A Theory of Human Motivation," Abraham Maslow (1943) presents the "hierarchy of needs" and establishes the concept that has been broadly used and studied by academicians and students since the last century. He sums up: "The basic human needs are organized in a hierarchy of relative prepotency" (MASLOW, 1943, p. 375), that could be resume as that a higher order need only emerges when the immediately lower need is relatively satisfied.

In the last decades, it almost became a routine to verify how a good number of Latin American countries cyclically, found themselves insome kind of social state of crisis. The complexity of crisis they faced led to a nonconsensual situation among academicians, in what relates to the consequent different treatments. In some countries, policies of populism opened a road to new ways of political representation, as well as mechanisms of sector representation. As a system of government, the main contribution of populism in these countries was the recognition of different social groups not included in politics so far. Nevertheless, they were not sufficient to modify the context of the layers of extreme poverty. Society becomes ashamed of its incapacity to understand such a social dynamic (MAX-NEEF, 1991).

Interesting to note that in 1973, and later in 1975, with the Declaration of Cocoyokand of the Dag-Hammarskjöld Report, the current debate at the United Nations Organization stated that the demographic explosion was due to poverty, while also, caused the strong power of natural resources devastation. Actually, there already was a consensus that such a destruction came with the materialism behind the high levels of consumption in industrialized nations (HOGAN; MARANDOLA JR; OJIMA, 2010; UNCTD, 2007).

This meant a substantial change in the perception that prevailed over development strategies. They now focused more on the satisfaction of human needs in a development panorama, requiring a new understanding of the reality (BIRSDALL, 2007).

From then on, it became a consensus in the academia that development and human needs are actually components of the only equation. This approach proved to go much further than an improvised case of a paradigm of a state in crisis. Since the beginning, such a postulate involves development a new ways of thinking about. The mentioned statement tries to see the world in a completely different, nonconventional perspective. Thus, it created the necessary conditions for a new approach of the theory of human needs. Better, it precisely is a new approach for the theory of human development. (MAX-NEEF, 1991). 
FAILURES IN BRAZILIAN PUBLIC SOCIAL PROGRAMS TO REDUCE EXTREME POVERTY: case

study Porto Alegre for all

Based on a survey developed with potential participants of the Programa Porto Alegre para Todos (Porto Alegre for All Program), the objective of the research is through a humanistic approach based on Max Neef's precepts, to understand the failure of the social program.

\subsection{Case Study - Porto Alegre for All Program}

In 2011, the City Government of Porto Alegre, Rio Grande do Sul, Brazil, one of the 12established member cities of the 2014 Soccer World Cup, created a 4-year social program named "Porto Alegre para Todos" (Porto Alegre For All). Besides fulfilling the International Federation of Football Association (FIFA)'s requirements to become a member city, the program had the objective of eradicating the extreme poverty in the Porto Alegre central region, aiming at an emancipation of citizens in such a condition.

In accordance with thestrategic planning, work plan and management tools avalibale for the Program, there were three major subprojects:Project 1) related and aiming to promote the professional inclusion of VTAs (carts) and VTHs Drivers, the program aimed to promote the entry of solid waste collection and waste separation workers in the formal labor market, as a counterpart to the gradual restriction of carts and trolleys circulation in Porto Alegre transit, and was determined by Law No. 3,581 /2008 but in fact, never really performes; Project 2) The program also aimed to promote a complete restructuring of the waste sorting units, looking to transform the reality of these popular enterprises, offering the necessary conditions for the pickers to have better income, well being at work and understanding the potential of their business.Project 3) the program edge also aimed to promote an increase in Environmental Education, enlarging action in schools, universities and municipal public agencies to reflect their inclusion and protection strategies, and looking for the mobilization of the whole city, to contribute and participate in the waste separation, sorting and recovery of post-consumer discarded materials.

As "potential candidates,"about 1800 families,were identified under the specific conditions and registered. They received information about theProgram and participated of several speeches offered by the Porto Alegre City members in charge. The Program had three main goals:

1. To enhance the traffic movement in the streets of Porto Alegre during the 2014 World Cup, not only to respond to FIFA's requirements, but also to remove the carts and horse-drawn carriages;

2. To raise the marginalized individuals' standard of living, including paper gathering, that often live in their own carts under subhuman conditions, always close to their 
raw materials: "downtown and its papers". For this reason, previous attempts to withdraw them from the downtown area were always unfruitful.

3. To promote these individuals' social inclusion, training themand hiring them in the public service of waste recycling, with the intention of raising their per capita income. This way, they would be included as common citizens, as government workers with the rights assured by the law, being able to hold documents, health insurance and educational support to their children. They could receive professionalizing studies through scholarships and the participation in events related to citizenship.

Nevertheless, a few months before ending the 4 years of the social program, less than $13 \%$ of the 1800 families were affiliated. The program seemed to be excellent as a social initiative, relying on the best conditions to enhance the extreme poverty of this group of citizens. A massive enrolment of these individuals and their families was expected. They still now present the minimal conditions of living, concerning health and education, perpetuating their children's and their own insertion in marginalized lives.

\section{LITERATURE REVIEW}

\subsection{Material goods and human needs}

McGregor (1960) explains Maslow'sTheory of Human Motivation (1954), as structured in five levels:

i) The lowest level, but greatly important when not fulfilled, are the physiological needs. The human being only looks for bread then there is no bread. Unless under special circumstances, needs of love, status and recognition are inoperative when the stomach is empty for a while. However, when individuals eat regularly and adequately, hunger is not a significant motivation. The same is true for other human physiological needs as rest, exercise, shelter, and time protection. A satisfied need not necessarily motivates the behavior. This is a fact of deep meaning, often ignored in traditional concepts.

ii) The needs in the upper level of the pyramid start to dominate the human behavior and to motivate individuals. They are the safety needs: need of protection against danger, threats and privation.

iii) When the human physiological needs are satisfied and there is no improvement in the physical well-being, then the social needs become a significant motivational factor for the human 


\section{FAILURES IN BRAZILIAN PUBLIC SOCIAL PROGRAMS TO REDUCE EXTREME POVERTY: caSe}

study Porto Alegre for all

behavior. This encloses requirements for participation in associations, inclusion and peer acceptance. In this aspect, interpersonal exchanges, friendship and affection become highly considered.

iv) In the next level, ego needs seem to belong to two different classes: related to selfesteem, self-confidence, accomplishment, competence, knowledge, independence, or needs related to the self-reputation, status, recognition, approval and respect from the group.

v) Finally, in the hierarchy of human needs there are those known as self-actualization needs. Each individual needs to actualize the own potential, the continuous self-development, a possibility of being creative, in the highest senseof the term, and growth in self-actualization (MASLOW, 1954). Through self-actualization, the human being finds a reason to live (Mc GREGOR, 1960). When the human needs are not fulfilled, a sense of frustration, aggressiveness, nervousness, insomnia, disinterest, passivity, low self-steem, pessimism, resistance to the new, insecurity and others. Other types of self-actualization can reward the negative feelings. (TAY; DIENER, 2011; GAMARINIKOW, 2013)

The theory of goodsis the practical reason to investigate human needs, beginning with the knowledge of such needs as explained in Psychology.While a philosophical theory concentrates upon the objectives that reflect over the nature and its contribution to the human excellence, the psychological theory of needs focuses upon individuals trying to understand how a human being moves and acts towards an objective, and trying to find purposes and direction of certain behaviors (MELÉ, 2009 , p. 75-6). Each human need influences the individual's motivation and actualization, letting him/her go ahead into other needs that follow a hierarchical order (MASLOW, 1954).

According to McIntyre (1998), the theory of needs implies different meanings:

a) Internal needs are qualitatively different and not replaceable by another;

b) There are several domains of social life that are different to individuals, and this includes family, work and politics with distinct meanings;

c) A good standard of life for individuals usually involves engagement in many or all these domains and practices.

Melé (2009) sees that real goods and needs present themselves to human rationality as objectives to be pursued. Such a rationality has been constant practice among business leaders and consumers, when they plan their actions. Shaw and Colimore (1988) tried to equalize Maslow's theory of self-actualization with the ideology of capitalism. These authors explain the economic individualism as consistent with the psychological individualism of the Humanist Psychology, while it emphasizes individuals' needs and desires as extremely important. According to these authors, Maslow's theory of human motivation implies that the worker is dedicated, perseverant, and the experience tends to raise himself/herself to the top of the pyramid. 
Prilleltensky (1994, p.82) explains the importance of individualities and their environmental influences, leading to the conclusion that "there are almost ilimited possibilities of changes in the individual". They can also drive to the conclusion that the change must happen inside the individual. In reality, the problem is in the individual, and not in the society level.

In their Theory of Self-determination (SDT), Deci and Ryan (2000) sustainthat understanding human motivation requires the consideration of the innate psychological needs related to competence, autonomy and kinship. Such a concept of needs relies upon the hypothesis that different regulatory processes are subjacent to the activities that distinguish them. They are differentially associated to the effective functioning and well-being of individuals, mainly due to different regulatory processes and contents associated to different degrees of needs satisfaction (RYAN; FREDERICK, 1997).

Tay and Diener (2011) developed a longitudinal study in 123 countries aiming at understanding the relationship between self-actualization and subjective well-being (SWB). These authors explain how, for years, the idea of unique and universal needs seemed to be overcome, as academicians were accepting the concept that socialization would mould the causes of well-being in each person and in each culture. Persons adapt themselves to the circumstances, so that in the end only the temperament influences the BES (KONNER, 2002; GAMARINIKOW, 2013).

Diener, $\mathrm{Ng}$, Harterand Arora (2010) focused in understanding the role of monetary resources as predictors of the social well-being, mainly of the basic and psychosocial needs. Their survey findings indicated that there really are predictors of the universal need of well-being (SWB). In the study, the income factor did not virtually represent any additional variation, suggesting a close correlation and proximity between basic human needsand the importance of the SWBattributes. There also are different types of SWB associated to psychosocial needs and they are correlated in a different way. Specifically, the social respect seems strongly related to positive feelings, while freedom relates to negative freedom.These approaches are compatible to the idea that respecting others, learning new things, and social relations of support are so much universal fundamental needs that they do not have to be compared to physiological basic needs to influence the SWB.

Ryffand Keyes (1995), and Ryan and Deci (2000), as Maslow (1954) before them, proposed that there are nonphysiological universal human needs. Their actualization is crucial to reinforce a person's feelings of well-being. These theoreticians suggest that psychological needsexist, and give as examples the deep social relationships, freedom and autonomy, associated to human beings. The actualization of these needs leads to higher SWB. The basic needs strongly relate to appraisals of life and negative feelings. These standards have been replicated in all regions of the world. 


\section{FAILURES IN BRAZILIAN PUBLIC SOCIAL PROGRAMS TO REDUCE EXTREME POVERTY: case \\ study Porto Alegre for all}

\subsection{Quality of life, needs and desires}

The literature presentsseveral studies related to scales of Quality of Life (QL) and its relationship with the human necessities. Constanza et al $(1997,2000,2007)$ proposed a Model of Human Needs QL,based upon a list of human necessities, to generate a set of indicators, either for quality of life, as for fundamental human needs.Quality of Life (QL) is a multidimensional construct that results from the appraisal of the individual is multiple needs. The needs were mainly a result of an integration of Max-Neef's studies "Human Needs Matrix" (1991), and Nussbaum and Glover's "A Study of Human Capabilities"(1995).

\subsection{Theoriesof rights and justice}

Pinzani (2009) argues that the human beings have needs beyond the need of rights. However, the conventional theories do notdispose a language in which these needs can be formulated as requirements of justice or can be so understood. This does not mean that any human requirement can legitimately become object of a justice claim, as this would mean to open a Pandora box. Before this, the idea is to find a theoretical point of view that allows enlarging the spectrum of legitimate justice requirements,beyond the mere legal pretensions. The concept of justice would not be enlarged to a point where it would lose the practical sense.

Moore (2000) verifies that there is no broadly accepted definition of happiness, but there are safe criteria to define suffering, particularly when it deals with a socially avoidable suffering. With such an expression, Moore (2000) indicates a suffering originated not by natural causes, as old age, illness or natural catastrophes, but are a result of human actions. It does not concern so much to immediate interpersonal relationships, but to general social relationships (MOORE, 2000).

By pointing out the social character of suffering, one could assign its responsibility to institutions or persons, in such a way that there might eventually emerge a correspondent duty of reparation (MARGALIT, 1996, DAVIDSON , 2108).The concept of capabilityintroduced by Amartya Sen (1999)and retaken with important changes by Martha Nussbaum, splitted into functioningandcapability. According to Sen (1999), certainfunctionalities have an intrinsic and independent valueas the corporal health, for example. Nussbaum (1990) stresses that, besides being intrinsic, in determined cases such a functioning represents a basis for freely acting: for instance, only one with a certain level of ability to read can lose it or improve it (NUSSBAUM; GLOVER, 1995).

Defining well-being as a possibility to freely chooseamong a broad spectrum of options, Sen (1999) sees the capabilities as possibilities or opportunities of functioning. They are not mere 
capabilities: saying that one has the capability to freely move himself/herself does not mean, according to Sen (1999), that it refers to its capability to displace, but to the options one concretely has. In this sense, the capabilities have to do not only with abilities, but also with the situations in which one finds himself/herself (as in the case of health)bad with external circumstances (SEN, 1999).

However, Nussbaum (1990) tends to consider capabilities either as traits, personal or of the individual's character. Traits. On one hand, she distinguishes internal capabilities, or conditions (corporal, mental or of the character) that make an individual able to choose among several functioning's that he/she considers valuable or, on the other hand, external capabilities related to external social and material conditions that make certain options actually available (Nussbaum, 1990, p.228). In this perspective, the institutional humiliation has to do with the fact that:(1) citizens in a State cannot develop their basic capabilities; and (2) state institutions are directly responsible for such a situation, or could change it, but do nothing. This should be different from the unconditional duties of a State toward its citizens. As an example, a State must offer its citizens a costless public elementary education. Citizens should be led to poorer conditions, or to an analphabetism that does not allow them to alleviate their poverty (NUSSBAUM, 2004, p.282).

\subsubsection{Theorecial framework}

The conditions of modern life offer only limited opportunities for these individuals, now out of the stereotypes of society. Despite being so significant, their needs seem relatively few, are not clearly expressed and consequently do not call attention of other citizens. The privation of the extreme poverty raises the most basic needs and drive their energy towards a daily struggle for fulfilling these needs (Mc GREGOR, 1960; DAVIDSON , 2018).

Relying on a sociological tradition, Veenhoven and Ehrhardt (1995) argue that in the "theory of habitableness," some societies present higher quality of life due to their universally desirable characteristics for humans. On the other hand, the anthropologist Edgerton (1992) stated that there are "sick societies" that do not produce joy and health. These approaches have in common the idea that certain circumstances are necessary to exist quality of life in all cultures and for all individuals. They also make clear that individual cultural differences may likely exist, in what people want and in what they see as reward and gratification, but these may coexist with the universal needs (KENRICKS et al., 2010). 


\section{$2.4 \quad$ Human Freedom}

Max-Neef's conceptof freedom (1991) is that of autonomy and determination, assuming equal rights and the capacity of disagreeing, choosing and developing the conscience.

Development is about people and not about objects. This is the basic postulate of Human Scale Development. The acceptance of this postulate-whether on intuitive, ethical or rational grounds-leads to the following fundamental question: How can we determine whether one development process is better than another? In the traditional paradigm, we have indicators such as the gross national product (GNP) that is in a way an indicator of the quantitative growth of objects. Now we need an indicator about the qualitative growth of people... (MAXNEEF, 1991, p.16)

The different perceptions and understandings are interwoven facets of the human needs issue. What is at stake here is a question of form and of emphasis. The challenge to all of us is to internalize an approach to development based on human needs, which, once understood, will guide our actions and expectations (MAX- NEEF, 1991, p.14-15).

According to Skinner (1971), freedom is a behavioral response to aversive stimulus that may vary between complete evasion and an aggressive attack. The author notes that, in one way or another, the intentional aversive control is the prevailing standard of social coordination. This includes family, government, economy, education and religion. Skinner believes that the environment moulds the individual. The autonomous human being would not exist as a concept: He/she is not free to make choices.

Among other opinions, Rolo May (1981) proposes freedom not only as a state of spirit, but as what distinguishes the human beings. The personal freedom allows individuals to think, feel and speak authentically. The author considers freedom "the mother of all values" (MAY, 1981, p. 6), as it gives the capacity of effectively value other assumptions. It serves as the basis for other human values as love, courage and honesty.

In "Development as Freedom" (1999), the Nobel Awarded economist Amartya Sen compares the concepts of freedom and agency. He understands agency as the capability of an entity (a person or other entity, humanor not) to act in any given environment. The author explains that, although an individual agency is fundamental for the development process, there is an unavoidable constraint caused by social and political agents, and the economic opportunities available in society. Recognizing the importance of both, either the individual freedom or the reality of social influences in the extensionof it, the expansion of individual freedoms means their final role in the development approach. Sen (1999) defines individual freedom as a social commitment in which society assumes the individual responsibility but also share the responsibility of the well-being of others. Social responsibility does not replace individual responsibility. On the contrary, it supports it. Substantive freedoms that the individual has (or not) are contingent, not only in personal, but also in social and environmental circumstances. 


\subsection{Family and production of the social}

The family institution is a relationship of domination based on civil equality of the "individual guarantees" that structure the private initiative.Under certain conditions, it isseen as an associated public relationship related to the production of the social (COIMBRA, 2001). There is a process to produce subjectivities, of right and wrong, that heads for institutionalizing a hegemonic model of family. It is placed in a conflicting position or through discrimination of other types of family relationships, as those constituted by single mothers, by relatives that take over the responsibilities of children, by separated couples, by parents that act illegally or immorally, although all of them are harmonious ways of family organization (COIMBRA, 2001).

According to Donzelot (1985), the social policy related to the poor in Brazil, per se, aims at the previsibility of the future. It is implicit that these families have few chances. They have no conditions to live the standards of the middle class order - as happens with poorest families - that cannot adhere to the established order. From this logic point of view, one deduces the resulting "need" of isolation or elimination of those "differentfrom the social public order", so that the system as a whole is not contaminated. Those who have in common a determined socioeconomic condition constitutes the main goal of policies:

[...] they are children and teenagers already in marginality or that will turn into it - because they are poor - that should be exterminated. The modernity requiresclean, aseptic cities, where misery - since it cannot be hidden and/or managed - should be eliminated, not for being overcome, but for the extermination of those that expose them, bothering the 'eyes, ears and noses' of wealthier classes (COIMBRA, 2001, p. 44).

The derived social categorization materializes in the individuals that develop themselves as independent entities, margin of historical middle class concepts, detached of the collective notion. In the context in which the individual is the key, the collective action also remains characterized in an individual way, as a sum, and not as product of collective agencies. Examples of this are the assistential works or public programs of poverty eradication. They are based in private interests taken to communities to generate demands, without giving room to the own groups to build their requests. Thus, the community concept becomes vague and it cannot be understood (DONZELOT, 1985).

This program aims to promote the social inclusion of these individuals by training and employing public waste garbage recyclers, with the aim of increasing per capita income, including as ordinary citizens, civil servants with rights guaranteed by law, as well as documents, health plans and educational aid to your children. In addition, other vocational courses were also offered (with the granting of a scholarship) and events in favor of citizenship. The program was open and optional (ie 
FAILURES IN BRAZILIAN PUBLIC SOCIAL PROGRAMS TO REDUCE EXTREME POVERTY: caSe

study Porto Alegre for all

adherence to the program was optional but labor rules should be respected and followed.) The program had a strong role (for success, or rather failure) in implementing the Municipal Fund Management Board of Encouraging Recycling and Productive Insertion of Waste Pickers (FMRIC)

\section{METHODOLOGY}

The research project was developed in two phases. First, with the support of an evangelic pastor engaged with the community, and with important members of this community, six qualitative depth interviews provided insights and helped to understand the main issues, later used as the Conjoint Analyses as attributes. The community is located in an area of difficult access from outside, quite violent and dangerous, what would not allow any other outsider to enter and do any survey without a local person together. Second, people suggested a soccer game for men and a gastronomy workshop for women. Later on, at the end, a "barbecue" was offered to all. In order to participate of this community event, the individuals identified themselves, filled out a questionnaire with social and demographical information, and hierarchically selected printed cards with options.Actually, by selecting cards was an application of the quantitative technique Conjoint Analysis. Conjoint Analyses is a survey-based statistical technique used in market research that helps determine how people value different attributes (feature, function, benefits).The technique seek to understand, what combination of a limited number of attributes is most influential on respondent choice or decision making (GREEN, P. E.; SRINIVASAN, 1990).

\section{RESULTS}

4.1 Phase 1: Analysis of the qualitative interviews

Recorded and transcribed, the interviews followed a semistructured script. The questions aimed at "Why people did not adhere to the Porto Alegre para Todos Program?." The content analysis was used to mainly verify the following aspects:

\subsubsection{Income}

"Yes, they know the program. For me there is no meaning in offering benefits and a formal job for these people. They don't care, they are very lazy and if they have enough to eat, it is fine" (Interviewed female 1, 45 years old).

"Yes, they know the program, but they don't trust it much. They think there is a personal political interest. They are very ignorant. It would be good that they had a steady wage, with responsibility and compliance with rules. But I think it is difficult, they want freedom to do 
whatever they want, to work when they want, to sleep, to drink ..." (Interviewed male 2, 55 years old).

"They love money, but they don't care to anything. I think it is a lot of drinks anddrugs. Freedom is all for them. They give this up at all. They are happier like this, unattached. Suffering to them is to have rules and being discriminated in the streets ..."(Interviewed male 6,38 years old).

According to May (1981) freedom is "the mother of all values," once it enables people to value other assumptions. Moore (1976) verifies that we do not have a generally accepted definition of happiness, but we have safe criteria to define suffering, mainly when the socially avoidable suffering is at stake.

\subsubsection{Activity}

"They don't want a boss. Those who went to a recycling firm are already crazy to come back. If they want more money, they work more and drink less ..." (Interviewed male 4, 48 years old).

"They prefer to have no rules and no bosses, so that they can remain drinking and doing whatever they want, which means, nothing, just idling" (Interviewed 3, 51 years old).

"See, women do better in the recycling firms, but the men are rebels, they are unsubmissive" (Interviewed female 1, 45 years old).

Skinner (1971) explains that freedom is a behavioral response to adverse stimulus that may vary between complete evasion and aggressive attacks. For this author, the environment moulds the individual. There is no such a concept as "autonomous man," that is free to do choices.

\subsubsection{Benefits}

\footnotetext{
"They barely know their children. They always had many women and still have many girlfriends. They do not care for their children's future. Women are more concerned"(Interviewed 6, 38 years old).

"I don't think they care about their children's future. They are very ignorant and these children have contact with drugs very early. They live the day. I believe they think that they might die tomorrow, everyday someone dies" (Interviewed male 2, 55 years old).

"They don't even think of retiring. There are many elderly people abandoned around here. I do not think they understand what this means. The future does not cross their minds" (Interviewed 3, 51 years old).
}

Sen's assumptions(1999) suggest that the freedom held - or not - by individuals are contingently, not only in personal, but also in social and environmental circumstances.

The interviews do not indicate that there is a real importance in a potential improvement of life and well-being, either for them or for their children. In these individuals' valued hierarchy, mainly in males' statements, it seems to be dedicated no value to their children's education. Retirement seems to be something quite distant, impossible for them to reach ever. 


\subsection{Results of the quantitative phase}

In the second quantitative phase, due to the heterogeneity of the sample (many respondents were analphabet) and with the respondents limited patience to fill out the questionnaire, the authors opted to use colored cardsapplying the Conjoint Analysis technique. The respondents were asked to classify the cards according to their preference. After this, the data went through statistical analysis using SPSS 20.0.This methodology has been applied by several researchers interested in determining the relative importance of attributes in the process of consumers' choices. With the conjoint analysis, we seek to establish functions of relative importance or utility, that describe the level of importance that individuals associate to the level of each attribute (HAIR et al., 2005).

The 98 respondents ( 85 adults males and 12 adults females)chose the described attributes (based in the qualitative phase)in 16cards indicating their three respective levels, based in the insights of qualitative interviews and the literature review. They appeared as follows (Table1):

Table 1 - Attributes and Levels for Conjoint Analysis

\begin{tabular}{ll}
\hline Attributes & \multicolumn{1}{c}{ Levels } \\
\hline Income & (i) Monthly income $-50 \%$ of the minimum wage (MW) \\
& (ii) Monthly income $-1 \mathrm{MW}$ \\
& (iii) Monthly income $-2 \mathrm{MW}$ \\
\hline Activity & (i) Formal Job (Brazilian CLT) \\
& (ii) Autonomous, independent \\
& (iii) Free lancer \\
\hline Benefits & (i) Formal retirement (Brazilian CLT) \\
& (ii) Scholarship for education \\
& (iii) Scholarship for children's education \\
\hline
\end{tabular}

Source: The authors (2018)

The respondents' description indicates mostly males (88\%), being seven (7) analphabets. Most of them finished - or almost finished - elementary school (Table 2 and Table 3)

Table 2 - Description of the Quantitative Sample - Educational Level

\begin{tabular}{|c|c|c|}
\hline Educational Level & $\mathbf{N}$ & $\%$ \\
\hline Analphabets & 7 & 7,0 \\
\hline Incomplete Elementary & 32 & 32,0 \\
\hline Complete Elementary & 49 & 50,0 \\
\hline Incomplete High-School & 10 & 10,0 \\
\hline Total & 98 & 100,0 \\
\hline
\end{tabular}

Source: The authors (2018)

Table 3 - Description of the Quantitative Sample - Age Level

\begin{tabular}{lcc}
\hline Age Level & $\mathbf{N}$ & $\%$ \\
\hline Less than 18 years & 3 & 3,0 \\
19 to 28 years & 22 & 22,0
\end{tabular}




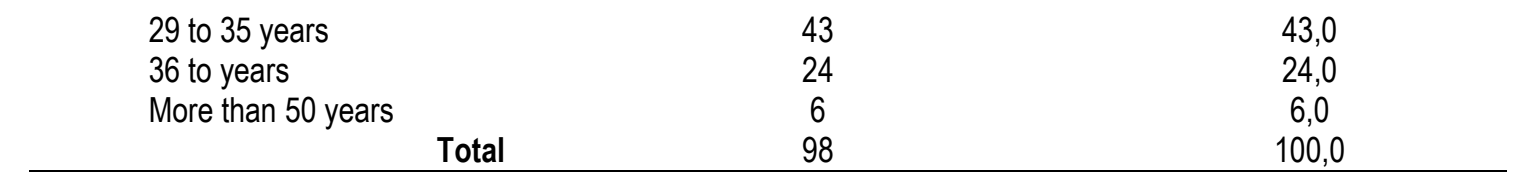

Source: The authors (2018)

The total of responded and classified cards was of 106. However, for the purpose of this project, only 98 were classified and considered valid.As in Table 4, most of the respondents had between 19 and 50 years of age. Table 5 shows information on civil status and number of children in the sample.

\subsubsection{Results of the quantitative research (Conjoint Analysis)}

Table 4 - Results and importance of attributes, utilities and levels of attributes

\begin{tabular}{|c|c|c|c|c|}
\hline Attribute & $\begin{array}{r}\text { Average } \\
\text { Importance }\end{array}$ & SD & Level & Utility \\
\hline \multirow{3}{*}{ Income } & \multirow{3}{*}{$22,45 \%$} & \multirow{3}{*}{0,905} & $\begin{array}{l}\text { Monthly income of } 50 \% \text { of a minimum wage } \\
\text { (MW) }\end{array}$ & $-0,9875$ \\
\hline & & & Monthly income of 1 (MW) & $-1,285$ \\
\hline & & & Monthly income of 2 (MW) & $-1,9272$ \\
\hline \multirow{3}{*}{ Activity } & \multirow{3}{*}{$65,24 \%$} & \multirow{3}{*}{0,75} & Formal job (Brazilian CLT) & $-0,3432$ \\
\hline & & & Autonomous & $-1,575$ \\
\hline & & & Free lancer & $-0,6472$ \\
\hline \multirow{3}{*}{ Benefits } & \multirow{3}{*}{$13,30 \%$} & \multirow{3}{*}{1,234} & Retirement - Brazilian CLT & $-0,8342$ \\
\hline & & & Scholarship for Education & $-0,2453$ \\
\hline & & & Scholarship for Children's Education & $-0,102$ \\
\hline
\end{tabular}

Source: The authors (2018)

The quantitative results (Table 4)show that the "Activity" attribute $(65,24 \%)$ had a higher utility or relative importance. The option for authonomous / independentactivity was relevant. Following, the "Income" attribute $(22,45 \%)$ indicates that the individuals are always looking for resources.

The "Benefits" attribute (13,30\%)represents the possibilityof having the respondents' retirement and scholarship for education, as well as scholarship for their children's education. This suggests no relevance for the sample.

TheSintax used in the SPSS 20.0to reach the results of the conjoint analysis is as in Figure 1:

Figure 1 - Sintax of the conjoint analysis SINTAX CONJOINTPLAN='C:IUsers|Gabriel LevrinilDocuments|DATACARTOES.sav'. 
FAILURES IN BRAZILIAN PUBLIC SOCIAL PROGRAMS TO REDUCE EXTREME POVERTY: caSe study Porto Alegre for all

IDATA=/RANK='Opçao1 Opçao2 Opçao3 Opçao10 Opçao11 Opçao12 Opçao13 Opçao14 Opçao15 Opçao16 Opçao4 Opção5 Opçao6 Opçao7 Opça08 Opçao9 '.

IFACTORS=Renda 'Rendames' (MORE) Atividade 'atividademes' (DISCRETE) Beneficos 'Beneficosmes' (DISCRETE). /RANK=RANK1 TO RANK16 /UTILITY='ORTHO.SAV'/PRINT=SIMULATION.

IOUTFILE= 'C:IUsersIGabriel LevrinilDocumentsIORTHOSAV.sav'.

/PRINT = Resume/PLOT/=ALL

Source: The authors (2018)

The quality of the responseswas supported using Spearman's coefficient (for variable metric response) of 0.998 and the Kendall's Tau correlation coefficient (for variable nonmetric response or ordination) that was 0.883 among the estimated preference values and the respondents' evaluations (real preference values).When the correlation coefficients are "low", there might be a respondents' no commitment with the survey (HAIRet al., 2005). The values of the Spearman and Kendall'sTaucoefficients close to "1" (one) indicate that the cards ordinations reflect the reality and demonstrate well-definedattributes (HAIR et al, 2005).

\section{CONCLUSIONS}

Poverty can be an economic circumstance, but it also a political issue, as it is directly influenced by decisions and actions taken by political agents for the good of the society. Summing up, governments distribute assets and resources, and decide who wins and how much to win (EASTON, 1965).

There is a consensus in the academic literature that fundamental human needs did not evolve much in their concepts and scope in the last decades. However, the Western way of doing things has significantly changed in the same period (KENRICKS, et al., 2010).The Universal Declaration of Human Rights recognizes the inherent dignity of equality and the inalienable rights of all human beings, based on freedom, justice and peace. Nevertheless, in our society paradigms of power and oppression are still present in many communities. The development of a conscious critique can increase our perception, recognition and understanding of why and how the fundamental needs are or will be fulfilled. The satisfaction of human needs reaffirms the search for harmony and balance that may increase the level of well-being in the individuals' lives.

\subsection{Freedom as the main need}


Paraphrasing Sen (1999) and Nussbaum (1990) point out the social character of suffering, believing that it should be possible to assign the responsibility for itinstitutions or to persons. A correspondent duty of reparation might eventually emerge from this. Amartya Sen (1999) introduced the concept of "capability", retaking it with Martha Nussbaum's significant changes (2003). Certain functionalities have an intrinsic and independent value. Nussbaum (2003) emphasize show in determined cases these functionalities, besides intrinsically valuable, represent a basis for freely acting. Sen (1999)suggests an unavoidable constraint caused by the social agents, politicians and economic opportunities available in society. It recognizes the importance of both individual freedom and reality of social influences. We were aligned with Nussbaum's concepts about intrinsic and independent values society segments, in our example extreme poverty. In addition, we are in accordance with Max-Neef (1991) and Sen's (1999) views about human needs.

Considering the survey sample categorization as of an extreme poverty, the emphasis the individuals imputed to "freedom" was effectively significant. It is not surprising, to the point as Max Neef's studies (1991) have given voice to the different needs of poor communities. For Sen (1999), freedom is a fundamental need, the end and the meaning of development, the main objective in a development process. In a way, it directly contrasts with the perspectives that consider the human, civil and political rights as secondary for the development. Individuals also seek for support for their individual freedoms in essential public services of education and health.

Deep understanding and concern about the different perspectives are crucial to elaborate what constitute the objectives and different ways to a primordial point in a humanist articulation of the development of a society (DAVIDSON, 2018; KRZNARIC, 2008). The capacity of a society to care the others is the basis of the human freedoms. The development of an empathy toward less protected and severely limited persons in what relates to their individual freedoms are fundamental requirements for a social transformation.

May $(1950,1981)$ emphasizes this consideration, explaining that freedom can be the root, the starting point of the main human needs. The assumptions of the Maslow's Theory find objections among academicians, as they reflect the needs of Western people. They would not take into account the poor countries, oppressed by totalitarian regimes, or native people with different culture and environment, basic aspects for Max-Neef'sfoundings(1991). This author rigorously identifies the importance of cultural and environmental differences in terms of what could defer and become the real fundamental needs of different cultures.

Concerning the creation of a thinking toward the future, Max Neef (1991) properly mentions the risk of committing mistakes in perception or in actions. Interpreting Max-Neef, in the case of Brazil's 


\section{FAILURES IN BRAZILIAN PUBLIC SOCIAL PROGRAMS TO REDUCE EXTREME POVERTY: case study Porto Alegre for all}

extreme poverty, the mistakes or badly succeeded actions for poverty eradication could have happened for misinterpretation of what becomes important for these individuals.

As contribution to the study, we mention the dissonance with the reality, on the side of political actors that created the social program Porto Alegre for All. Clearly, these individuals do not want schedules and norms. They do not like rules, mainly in the job. In their world, it is very important to be free to go and come, to work or not, even though the Western society keeps them apart, as pariahs for the society. These individuals' apparent depression, if existent, is merely circumstantial and momentary. In their world, they have no interest in finding a job, being legally hired, and retiring.

Max-Neef (1991) explains that in societies of extreme poverty, diversity and autonomy should be preserved in their space, as these individuals will be the protagonists of the future.

The social politics toward the poor in Brazil, per se, indicate destiny previsibility. Few chances for these families are implicit. They have no conditions to live according to the parameters of the middle-class order - as happens with poorest families -that cannot adhere to the instituted order. With this logic, it is possible to notice the resulting "necessity" of isolation or elimination of the "different from the social public order", so that the system is not totally contaminated (DONZELOT, 1985).

This is not the same as to say that society and governments should not act for the improvement and well-being of these communities, mainly in what relates to children's health and education. The mother's presence is the main reference to these children. When they mention family, they mention the mother. The father is never present.Family degradation and diversity of religions in these environments are also notorious, although not necessarily a novelty.

\subsection{Contributions and managerial implications}

The following recommendations are the authors' contributions for public agents or private institutions that face these challenges:

a) The programs should survive to the extremely poor individuals' "resistance to changes" should be preferably understood and supported by people relying on their past experiences, and not on institutional basis limited by individuals with different social values. It is clear that normal rules in the "the hierarchy of jobs" do not work well in this social segment. The adherence to programs will hardly occur following rules of the individuals "called normal" in the actual social standards. Individuals should become productive within this reality, the needs and desires of this group.Some types of temporary jobs and diverse ways or raising self-steem suggest they are an effective way of treating the adult male population. The goal is 
that the individuals have and accumulate positive experiences, as a result from their conduct and attitude.

b) They are long-term programs, in which the maternal pillar has to be preserved, sustaining the family concept nowadays.Education and health will be oriented toward these women, who really became the children's reference. The economicfinancial and emotional stabilization that the mother provides suggests that the future of the children may effectively change.

c) The public policies of intervention should concentrate in the nature of this poverty adherents' resistance. It goes beyond a hermeneutic interpretation, seeking a fusion of the attitude genesis and the experimental process that this attitude provides. Programs fail because their focus was the analysis of the program development process in their several levels, especially the "environmental factor," and they do not seek for responses in this group's values and needs. They do not look for an emotional stability and recovering of the self-esteem that may orient this group's social inclusion. Summing up, the inability of public policies' builders to recognize the "target" group's differences, that go beyond their own socially expressed preferences, does neither produce program results or goals nor reach the "target" group's fundamental needs.

\section{REFERENCES}

BIRDSALL, N. The Impact of Globalization on the World's Poor: Proceedings of the Panel. Washington, D. C.: The Brookings Institution, May 16, pp. 26-37, 2007.

COIMBRA, C. M. B.Operação Rio. Rio de Janeiro: Oficina do Autor e Intertexto, 2001.

CONSTANZA, R.; CUMBERLAND, J.C.; DALY, H.E.; GOOGLAND, R.; NORGAARD, R.An Introduction to Ecological Economics. Boca Raton: St. Lucie Press, 1997.

CONSTANZA, R; FISHERA, B.; ALIB, S. ; BEERC, C. ; BONDD, L; BOUMANS, R.; DANIGELIS, N.; DICKINSON, J.; ELLIOT, C.; FARLEY, J.; GAYER, D. E.;GLENN, L. M.; HUDSPETH, T; MAHONEY, D.; McCAHILL, L.; McINTOSCH, B.; REED, B.; RIZIVI, S. A. T.;RIZZO, D. M.; SIMPATICO, T.,SNAPP, R. Quality of life: An approach integrating opportunities, human needs, and subjective well-being Ecological Economics (61) 2-3,pp. 267-276, May 1. 200. Doi:

10.1016/j.ecolecom.2006.02.023 
DAVIDSON , D. J (eds) Environment and Society: Concepts and Challenges,Editors: Boström, Magnus, 2018.

DECI, E. L.; RYAN, R.M. The "what" and "why" of goal pursuits: Human needs and the selfdetermination of behavior. Psychological Inquiry(11) 4, pp. 227-268, 2000. Doi: 101207/S15327965PLI1104_01

DIENER, E.; NG, W.; HARTER, J.; ARORA, R.Wealth and happiness across the world: Material prosperity predicts life evaluation, whereas psychosocial prosperity predicts positive feeling. Journal of Personality and Social Psychology(99) 1, pp.52-61, July, 2010.Doi:10.1037/a0018066

DONZELOT, J.A Polícia das Famílias. Rio de Janeiro: Graal Ed., 1980

EASTON, D. A Framework for Political Analysis. Chicago and London: The University of Chicago Press, 1965.

EDGERTON, R. B.Sick Societies: Challenging the myth of primitive harmony.New York, NY: Free Press, 1992.

GAMARINIKOW, E. Educação, (in)justiça social e direitos humanos: combatendo desigualdades na globalização turbocapitalista, Revista Brasileira de Educação v. 18 n. 52 jan.-mar. 2013.

GREEN, P. E.; SRINIVASAN, V. Conjoint Analysis in Marketing: New Developments with Implications for Research and Practice, Journal of Marketing, Vol. 54, October 1990, 3-19, 1990.

HAIR, J.; ANDERSON, R.; TATHAM R.; BLACK, W. Análise Multivariada de Dados. 5 ed., Porto Alegre: Bookman, 2005.

HOGAN, D. J.; MARANDOLA Jr., E.; OJIMA R.População e Ambiente: desafios à sustentabilidade. São Paulo: Blucher, 2010.

KENRICKS, D. T.; GRISKEVICIUS, V.; NEUBERG, S. L.; SCHALLER, M. Renovating the pyramid of needs: Contemporary extensions built upon ancientfoundations. Perspectives on Psychological Science. (5) 3, pp.292-314, May, 2010.Doi: 10.1177/1745691610369469.

KONNER, M. J. The Tangled Wing: Biological Constraints on the Human Spirit, 2 ed. (original 1982) New York: Times Books, 2002.

MACINTYRE, A. Politics, Philosophy and the Common Good.In: KNIGHT, K. (ed.)The Maclntyre Reader. p. 235-252, 1998.

MARGALIT, A. The Decent Society. Traduzido por Naomi Goldblum. Massachusetts: Harvard University Press, 1996.

McGREGOR, D. The Human Side of Enterprise. New York: McGraw-Hill, 1960.

MASLOW, A. H. A theory of human motivation. Phsychological Review. (50) 4, p. 370-396, July, 1943. 
MAX-NEEF, M. Human Scale Development: Conception, application further reflections. NY, London: Apex Press, 1991.

MAY, R. Freedom and destiny. New York: W. W. Norton \& Company, 1981.

McGREGOR, S. The Politics of Poverty. Melbourne: Penguin Book, 1982.

MELE, A. R. Effective Intentions: The power of conscious will. Oxford: University Press, 2009.

MOORE, J. W Environmental Crises and the Metabolic Rift in World-Historical

Perspective". Organization and Environment. 13 (2): 123-158,

2000. Doi:10.1177/1086026600132001.

NISSANKE, M; THORBECKE, E. The Impact of Globalization on the Worls's Poor:

Transmission merchanisms. Paper prepared for the WIDER Jubilee Conference in Helsinki, June pp.17-8, 2005.

NUSSBAUM, M.; GLOVER, J. (orgs.). Women, Culture, and Development. A study on human capabilites. Oxford: Clarendon Press, 1995.

NUSSBAUM, M., Women, Culture, and DevelopmentPhilosophy and Phenomenological Research(68)2, p. 473-486,March, 2004.

PINZANI, A.Reconhecimento e Solidariedade. Revista ethic@.(8)3, pp. 101-113, Maio, 2009.Doi: 105007/1677-2954.2009v83p101,

PRILLETENSKY, I. The morals and politics of Psychology: Psychological discourse and the status quo. Albany, NY: State University of New York Press, 1994.

RYAN, R. M.; DECI, E. L.Self-determination theory and the facilitation of intrinsic motivation, social development, and well-being. American Psychologist. (55)8, p. 68-78. January, 2000.Doi: 10.1037/0003-066X55.1.68

RYAN, R. M.; FREDERICK, C.On energy, personality and health: Subjective vitality as a dynamic reflection of well-being. Journal of Personality. (65)3, pp. 529-565, September, 1997. PMID 9327588

RYFF, C. D.; KEYES, C. L. M. The structure of psychological well-being revisited. Journal of Personality and Social Psychology. (69) 4, pp.719-727, October, 1995.

SEN, A. Development as freedom. New York: Anchor Books, 1999.

SHAW, R.; COLIMORE, K. Humanistic psychology as ideology. Journal of Humanistic Psychology, 28(3), pp. 51-74, July, 1988.Doi: 10.1177/0022167888283004.

SKINNER, B. F. Beyond freedom and dignity. New York: Alfred A. Knopf, 1971.

TAY, L., DIENER, E. Needs and subjective well-being around the world. Journal of Personality and Social Psychology. (101) 2,p. 354-365, 2011.Doi:10.1037/a0023779 
FAILURES IN BRAZILIAN PUBLIC SOCIAL PROGRAMS TO REDUCE EXTREME POVERTY: caSe study Porto Alegre for all

UNITED NATIONS CONFERENCE ON TRADE AND DEVELOPMENT (UNCTD). (2007). Least developed countries Report, 2007. Retrieved July 15, 2008, from

http://www.unctad.org/Templates/WebFlyer.asp?intltemlD=4312\&lang=1. Access: 10 mar. 2018.

VEENHOVEN, R.; EHRHARDT, J.The cross-national pattern of happiness: Test of predictions implied in three theories of happiness. Social Indicators Research. v. 34, n.1, p. 33-68, January, 1995.Doi: 10.1007/BF0107896 